\title{
A INFLUÊNCIA DA GESTÃO FAMILIAR, NO SEGMENTO DE CONSTRUÇÃO CIVIL, NA AVALIAÇÃO DE DESEMPENHO ORGANIZACIONAL
}

\section{THE INFLUENCE OF FAMILY MANAGEMENT IN ORGANIZATIONAL PERFORMANCE ASSESSMENT AT CIVIL CONSTRUCTION SEGMENT}

\author{
Leonardo Fabris Lugoboni \\ São Paulo, SP, Brasil \\ E-mail: leonardo.lugoboni@fecap.br \\ Marcus Vinicius Moreira Zittei \\ Comércio Alvares Penteado. \\ São Paulo, SP, Brasil \\ E-mail: marcuszittei@zittei.com.br

\section{Stefhany Ariane Barros} \\ Especialista em Controladoria pela Fundação Escola de Comercio Alvares Penteado. \\ São Paulo, SP, Brasil \\ E-mail: stefhanybarros@hotmail.com
}

Doutor em Administração pela Universidade de São Paulo. Professor na Fundação Escola de Comercio Alvares Penteado.

Doutor em Ciências Contábeis e Administração pela Fundação Universidade Regional de Blumenau. Professor na Fundação Escola de

\section{Elubian de Moraes Sanchez}

Doutoranda em Contabilidade e Controladoria pela Universidade de São Paulo, Mestre em Contabilidade e Controladoria pela

Universidade de São Paulo.

São Paulo, SP, Brasil

E-mail: elubiansanchez@gmail.com

\section{RESUMO}

As empresas familiares enfrentam, por essência, vários desafios. Deste modo, a competição faz com que estas recorram a estratégias que as auxiliem a aumentar seu desempenho. Dentre essas estratégias, encontra-se a prática de gestão do desempenho organizacional, foco deste estudo. Entretanto, em muitos casos as relações profissionais colidem com as relações familiares, e devido à influência dos aspectos culturais, a profissionalização desse tipo de organização torna-se um desafio. Partindo dessa premissa, o objetivo desta pesquisa foi avaliar os principais aspectos culturais em empresas familiares e como eles afetam a gestão do desempenho organizacional. Para atingir este objetivo, realizou-se uma pesquisa de natureza exploratória, por meio de um estudo de caso múltiplo. $\mathrm{O}$ estudo compreendeu quatro empresas familiares dentro do segmento de construção civil, utilizando a entrevista semiestruturada como técnica para coleta de dados. Constatou-se que todas as empresas estudadas têm a presença da família na gestão e a cultura organizacional é permeada pelos valores do fundador. No momento de tomada de decisão, há a presença de opiniões da família, inclusive de integrantes que não participam da administração e, por consequência, a decisão final é centralizada nos fundadores. As empresas da amostra utilizam como ferramenta de gestão do desempenho os indicadores financeiros e não financeiros, entretanto, esta ferramenta está sobre a influência da cultura organizacional e dos gestores familiares. Não houve, entretanto, evidências que permitissem a conclusão de que tais características comprometessem ou não a continuidade dessas organizações.

Palavras-chave: Gestão do desempenho. Empresas familiares. Indicadores. Cultura. Cultura organizacional. Construção Civil.

\section{ABSTRACT}

Family businesses face, in essence, a number of challenges. In this way, competitiveness makes them resort to strategies that help them increase their performance. Among these strategies is the practice of organizational performance management, the focus of this study. However, in many cases professional relationships collide with family relationships, and due to the influence of cultural aspects, the professionalization of this type of organization becomes a challenge. Based on this premise, the objective of this research was to evaluate the main cultural aspects in family businesses and how they affect organizational performance management. To achieve this objective, an exploratory research was carried out, through a multiple case study. The study comprised four family companies within the civil construction segment, using the semi-structured interview as a technique for data collection. It was verified that all the studied companies have the presence of the family in the management and the organizational culture is permeated by the values of the founder. At the moment of decision making, there is the presence of opinions of the family, including members who do not participate in the administration and, consequently, the final decision is centralized in the founders. The sample companies use financial and nonfinancial indicators as a performance management tool, however, this tool is about the influence of organizational culture and family managers. There was, however, no evidence to conclude that such characteristics would compromise the continuity of these organizations.

Keywords: Performance management. Family-run businesses. Indexes. Culture. Organizational culture. 


\section{INTRODUÇÃO}

Com o atual cenário da economia, caracterizada pela competitividade que norteiam as organizações, torna-se de extrema importância a realização de estudos que venham contribuir para o aumento da eficiência e eficácia organizacional (LIMA, OLIVEIRA e OLIVEIRA, 2016). Deste modo, as organizações precisam saber avaliar seu desempenho, pois sua continuidade depende da efetividade de seus instrumentos de gestão, sendo assim, tais instrumentos servem como ferramenta, conduzindo um gerenciamento eficaz (SOMENSI e TONTINI, 2001).

Nesse sentido, Abreu et al. (2008) afirmam que, a prática de avaliar é intrínseca à própria natureza humana, uma vez que esse baseia-se na análise e julgamento de determinado fato, ideia, objetivo e, do mesmo modo na tomada de decisão, com a intenção de se atingir uma situação desejada. Deste modo, as empresas buscam, através da gestão do desempenho, controlar suas atividades com o objetivo de examinar o resultado de suas atitudes.

Historicamente, as técnicas de gestão de desempenho organizacional têm passado por diversas mudanças. Atualmente, o mundo organizacional tem exigido olhos voltados à novos modelos de gestão. Desta forma, a gestão do desempenho torna-se ferramenta gerencial, para que se possa atingir os objetivos propostos com sucesso (CERETTA e QUADROS, 2003; DUTRA, 2005).

Saber determinar o que deve ser medido e avaliado não é uma função simples, depende da complexidade do processo e da importância em relação às metas definidas pela empresa (ALMEIDA, CALLADO e CALLADO, 2008a). Deste modo, a gestão do desempenho deve estar atrelada ao ambiente em que a empresa está inserida.

A gestão de desempenho é um processo dinâmico, ou seja, ao longo do tempo as medidas a serem avaliadas vão mudar (BITITCI, CARRIE e SUWIGNJO, 2000). Begemann, Bititci e Turner (2000) complementam que, o sistema de medição de desempenho deve ter: a) monitoramento externo e interno, analisando a evolução e mudanças; b) um sistema de análise que utiliza os monitoramentos internos e externos para definir prioridades; e c) um sistema de implantação.

De acordo com Borges e Carvalho (2011), a gestão do desempenho é particular a cada empresa, e deve ser estruturada para abranger os critérios de sucesso relevantes à organização, e que estejam atrelados à expectativa das partes relacionadas.

Nesse sentido, os instrumentos de gestão devem estar em harmonia com a cultura organizacional e medir a eficiência da empresa em relação ao ambiente externo, pois assim, o gestor pode se preparar para enfrentar as mudanças ambientais (BENEDICTO e PADOVEZE, 2005; MACEDO e SILVA, 2005). De acordo com Kich e Pereira (2009), a busca sobre Cultura Organizacional na administração, passou a se dar na década de 80, buscando nela o apoio para a maioria das estruturas sobreviverem no mundo dos negócios.

O fundador, principalmente em empresas familiares, normalmente é o principal administrador da empresa, e a cultura organizacional, na maioria das vezes, é um reflexo dos seus valores e crenças (FERREIRA e LOURENÇO, 2012).

Nesse contexto, o desafio da profissionalização da gestão nesse tipo de empresa representa um passo de extrema importância para a sua perpetuidade no mercado (OLIVEIRA e PAPA, 2009). 
Estima-se que as empresas familiares ocupam posição significativa na economia brasileira e mundial, estando presentes em diferentes setores, desde pequenas empresas até grandes multinacionais (BEUREN, HEIN e ORO, 2009; BEUREN e GRANDE, 2011).

Ante ao exposto surge o seguinte questionamento: Como a cultura organizacional afeta a "gestão de desempenho" de uma empresa familiar?

O objetivo desta pesquisa é avaliar os principais aspectos culturais em empresas familiares e como eles podem afetar a gestão do desempenho organizacional.

Altaf e Troccoli (2010) complementam que a importância das empresas familiares brasileiras é resultado de seu elevado número no mercado, do volume de empregos que geram, do número de empreendimentos consolidados e da influência econômica.

Com relação à importância do segmento escolhido, o segmento da construção civil possui participação significativa na estrutura do PIB. Segundo dados da FIESP (2015), a construção civil ocupa $13,5 \%$ de toda força de trabalho do país. A pesquisa ainda aponta, que o segmento em geral de construção civil detinha $51,4 \%$ do PIB setorial, portanto, foi o que mais contribuiu com a atual retração. Portanto, com a economia em retração, a competitividade entre as empresas cresce e ser eficaz pode ser o caminho para se manter no mercado. A eficácia pode ser medida por meio da gestão de desempenho organizacional, logo, tal ferramenta torna-se importante em períodos de alta competitividade. Sendo assim, justifica-se a razão e a importância do tema, tendo em vista que a continuidade das empresas requer, dentre outras coisas, uma efetiva medição de desempenho, e a cultura por sua vez, pode influenciar na gestão do desempenho das empresas familiares (BEUREN e MARCELLO, 2016).

Esta pesquisa destina-se aos gestores de empresas familiares interessados em como a gestão do desempenho pode ser um importante instrumento de controle, e como a cultura organizacional pode influenciar no desempenho.

\section{REFERENCIAL TEÓRICO}

\section{CULTURA ORGANIZACIONAL}

A cultura é um bem exclusivo do ser humano, nela pode-se encontrar os elementos que compreendem o comportamento, sentimentos e motivação das pessoas, tanto no campo individual como no coletivo (JIMÉNEZ, MEDINA e SILVA, 2013).

A cultura pode ser um aspecto de cada povo, comunidade, organização, família, devido a isto, pode ser vista de formas diferentes, de acordo com o que cada indivíduo acredita. Nesse sentido, os indivíduos mesmo com suas diferenças, compartilham suas experiências. O mesmo acontece com as organizações, portanto, este fenômeno pode ser caracterizado como cultura organizacional (RAMOS, SOUZA e WEHRLE, 2016).

Nesse sentido, Lima, Oliveira e Oliveira (2016) complementam que a cultura de uma organização é um conjunto de valores e crenças compartilhados que inspiram o comportamento daqueles que os compartilham. 
Desta forma, a cultura organizacional tem sido caracterizada como um fator de muita importância nas práticas de gestão, pois desempenha a função de orientar como a empresa administra seus negócios, definindo o motivo de sua existência. Desse modo, estabelece os valores culturais, definindo o meio de cumprir a missão da organização (BENEDICTO e PADOVEZE, 2005; CRUZ e FERREIRA, 2015).

\section{Empresas Familiares}

De acordo com Teló (2001), empresa familiar pode ser caracterizada pela junção de esforços e recursos para determinada finalidade, com a presença da família na organização. Há diferentes perspectivas para que uma empresa se caracterize como familiar. No Quadro 1, estão resumidos alguns conceitos citados por renomados autores.

Quadro 1 - Conceitos de empresa familiar

\begin{tabular}{|l|l|}
\hline \multicolumn{1}{|c|}{ Autores } & \multicolumn{1}{c|}{ Conceito } \\
\hline Donnelley (1964) & $\begin{array}{l}\text { São aquelas que estejam ligadas a uma família e quando essa ligação resulta em uma } \\
\text { influência na política da empresa, nas diretrizes empresariais, nos interesses e objetivos } \\
\text { durante um prazo de no mínimo, duas gerações. }\end{array}$ \\
\hline Bernhoeft (1987) & $\begin{array}{l}\text { São aquelas que tem sua origem e sua trajetória ligadas a uma família, ou aquelas que } \\
\text { mantém membros da família na gestão dos negócios. }\end{array}$ \\
\hline $\begin{array}{l}\text { Chrisman, Chua e } \\
\text { Sharma (2005) }\end{array}$ & $\begin{array}{l}\text { É caracterizada pelo envolvimento da família sobre a direção estratégica e pela intenção da } \\
\text { família em manter o controle. }\end{array}$ \\
\hline $\begin{array}{l}\text { Cario et al. (2010) } \\
\text { A caracterização de uma empresa familiar baseia-se na história de uma organização que tem } \\
\text { sua existência atrelada a uma família. }\end{array}$ \\
\hline $\begin{array}{l}\text { Albuquerque, } \\
\text { Oliveira e Pereira } \\
\text { (2012) }\end{array}$ & $\begin{array}{l}\text { A definição de empresas familiares geralmente passa por três aspectos: o controle acionário, } \\
\text { o envolvimento da família na gestão do negócio e a transferência entre gerações. Neste } \\
\text { sentido, a participação da família em um ou mais desses aspectos, configura o caráter familiar } \\
\text { de uma empresa. }\end{array}$ \\
\hline $\begin{array}{l}\text { Borges, Brito e } \\
\text { Lescura (2012) }\end{array}$ & $\begin{array}{l}\text { A empresa é caracterizada como familiar quando há aspectos do universo familiar no } \\
\text { ambiente dos negócios, bem como assuntos pertinentes à rotina empresarial presentes em } \\
\text { discussões familiares. }\end{array}$ \\
\hline
\end{tabular}

Fonte: Elaborado pelos autores

Nesse sentido, Beuren e Müler (2010) complementam que algumas empresas podem ser administradas por outras, por outro lado, se um integrante da família permanecer na gestão, a empresa não perde a característica de familiar.

As empresas familiares apresentam peculiaridades que despertam o interesse dos pesquisadores, pois tornam sua gestão diferenciada das demais organizações (BORGES, BRITO e LESCURA, 2012). Desse modo, a cultura organizacional adotada em empresas familiares influencia na gestão desse tipo de empreendimento. 
Cultura Organizacional em Empresas Familiares

Os aspectos culturais nas empresas familiares possuem características específicas, pois envolvem a família nas decisões administrativas. Nesse sentido, a maior influência na origem de sua cultura é a cultura da família e de seu fundador, pois, os integrantes da família transferem seus valores para o ambiente que estão inseridos (MAIA, 2009; BEUREN e MÜLER, 2010).

Nesse sentido, as relações entre a unidade familiar e os negócios da entidade representam laços muito fortes. Logo, tais relações dentro da organização geram um impacto significativo nos negócios, muitas vezes impedindo o desenvolvimento das organizações (CHRISMAN, CHUA e STEIER, 2005; CATER e SHWAB, 2008).

Deste modo, os dois sistemas que formam esse tipo de negócio: a empresa e a família, possuem características opostas, uma voltada para a eficiência e eficácia, e outra para aspectos afetivos, logo, as regras entram em confronto, originando possíveis conflitos. Deste modo, as tentativas de adaptação da unidade familiar na organização, normalmente prejudicam ambas, família e empresa. Para isso, devem ser criadas regras de convivência entre a empresa e a família, para que exista maior comprometimento entre as partes (RODRIGUES, 1991; BETHLEM, 1994; MAIA, 2009).

Na concepção de Donnelley (1964) o interesse familiar é o motivo da fraqueza das empresas. Em sua pesquisa, o autor destaca as principais fraquezas da administração familiar como sendo: a) conflitos de interesse entre a família e a empresa; b) falta de disciplina na distribuição dos lucros; c) lentidão nas reações das imposições do mercado; e d) nepotismo.

Dentre os principais problemas organizacionais em empresas familiares, Donnelley (1964) destaca que, o nepotismo é o mais evidente. Rodrigues (1991) complementa que, o fato de pertencer à família não é suficiente para satisfazer as exigências gerenciais da organização. Nesse sentido, as empresas familiares tornam-se organizações de sucesso quando os administradores criam regras organizacionais para garantir que a participação da família só aconteça se for para contribuir com a consolidação da empresa (DONNELLEY, 1964).

Chrisman, Chua e Steier (2008) complementam que, a flexibilidade estratégica depende da cultura adotada pela empresa. Portanto, o papel da família é transferir essa perspectiva de desempenho organizacional para todos os membros da organização e adotar uma cultura que atendam às necessidades de mercado. 


\section{Gestão do Desempenho Organizacional por Meio de Indicadores De Desempenho}

Um aspecto que possui grande ligação com a cultura organizacional é a forma como se realiza a gestão do desempenho.

Há algumas décadas, os modelos de planejamento estratégico se delimitavam à aspectos qualitativos e quantitativos de fácil mensuração. Tais aspectos não se preocupavam em conectar os objetivos estratégicos da empresa com a operacionalização (GASPARETTO, LUNKES e SCHNORRENBERGER, 2014).

Para suprir essa necessidade, a partir da década de 80, diversos modelos de indicadores de desempenho têm sido desenvolvidos com a finalidade de fazer a mensuração da performance organizacional e para a definição das variáveis que melhor representam o desempenho geral da empresa (ANDRADE, CALLADO e CALLADO, 2009; CORSO, CRUZ e MARTINS, 2011).

Os indicadores podem ser divididos em duas categorias: financeiros e não financeiros (ANDRADE, CALLADO e CALLADO, 2009). Nesse sentido, a utilização de indicadores financeiros ainda é o método mais comum e possui inúmeras pesquisas que comprovam sua eficiência (MACEDO, MARQUES e RIBEIRO, 2012).

Diversos indicadores financeiros são utilizados na literatura para a gestão do desempenho organizacional, dentre os indicadores mencionam-se: indicadores de liquidez, indicadores de atividade, indicadores de endividamento, indicadores de rentabilidade e indicadores de análise de ações (BEUREN e DALLABONA, 2015). Entretanto, a simples utilização de indicadores financeiros como forma de medição de desempenho torna-se questionável, pois, a utilização desses indicadores é muito relativa e não leva a empresa a aperfeiçoar seus objetivos e metas (CELESTINO e SILVA, 2011).

Atualmente, tem se aumentado a percepção de que outros fatores importantes para as organizações não podem ser capturados pelos indicadores financeiros. Deste modo, surgem os indicadores não financeiros, como ferramenta para medir o desempenho estratégico organizacional e superar possíveis falhas apresentadas pelos indicadores financeiros tradicionais (CERETTA e QUADROS, 2003; NEELY, 2007; DIENG, MORAES JÚNIOR e REZENDE, 2011). Neely (1999) complementa que, esse interesse atual se deu por diversos motivos, destacando o aumento de concorrência e a modificação das demandas externas.

Nesse contexto, Kaplan e Norton (2004) consideram que, em muitas organizações o conhecimento de seus colaboradores, os sistemas de informação e sua cultura organizacional valem muito mais do que seus ativos tangíveis, pois são mais difíceis de ser imitados por seus concorrentes, tornando-os uma ferramenta para adquirir vantagem competitiva. Sendo assim, a empresa que souber calcular seu valor, poderá avaliar e conduzir sua posição competitiva com mais facilidade e exatidão. Portanto, a mensuração do valor gerado por esses ativos torna-se útil para a gestão estratégica (HABBERSHON e WILLIAMS, 1999; DIENG, MORAES JÚNIOR e REZENDE, 2011).

Através da utilização de indicadores de desempenho, os gestores podem analisar a qualidade da performance organizacional e consequentemente, podem tomar decisões convictas sobre a estratégia, além de acompanhar a evolução dos resultados (ALMEIDA, CALLADO e CALLADO, 2008a; ALMEIDA et al., 2012). Teló (2001) complementa que, aquilo que a empresa define como indicador é o que ela vai buscar como resultado. 


\section{Gestão do Desempenho em Empresas Familiares}

Vivemos em uma sociedade dinâmica e em constante evolução. Logo, a adaptação às exigências de mercado, torna-se cada vez mais uma questão de sobrevivência (TELÓ, 2001). Tal sobrevivência pode estar atrelada em como as empresas familiares fazem a gestão de seus recursos financeiros, recursos humanos, tecnologias e processos, ou seja, onde exista a necessidade de decisões referente diferentes áreas fazemse necessário a gestão do desempenho, onde se pretende identificar se a estratégia está sendo atingida (BORTOLUZZI, ENSSLIN e ENSSLIN, 2011).

Para Silva (2014), uma gestão ineficaz originada pelo despreparo dos gestores, conduz a empresa à mortalidade. Esta falta de preparo está diretamente ligada à falta de adoção das novas práticas de gestão. Desse modo, a família pode ser fonte de vantagens e também de limitações ao desempenho de empresas familiares, devido à influência nos aspectos administrativos. Nesse sentido, a profissionalização desse tipo de organização torna-se um desafio (MAIA, 2009; BARBOSA, COSTA e SOUZA, 2013).

O termo profissionalização pode ser definido como o processo pelo qual uma empresa familiar adota práticas administrativas mais racionais (SILVA, 2014). Tal profissionalização deve ser adotada também por empresas familiares. Teló (2001) complementa que, o desenvolvimento de um processo gerencial requer um esforço contínuo de seus administradores para projetar e implantar sistemas de medição e gestão do desempenho organizacional.

Nesse sentido, é importante observar que a gestão do desempenho é parte integrante no suporte ao processo da administração que busca a competitividade (TELÓ, 2001; ALMEIDA, CALLADO e CALLADO, 2008b).

O processo de conduzir a gestão do desempenho, precisa atender os seguintes critérios, conforme Bortoluzzi, Ensslin e Ensslin (2011): a) ser desenvolvido de forma personalizada, associados às particularidades do ambiente que se propõe avaliar; b) perguntar aos gestores quais os objetivos para o contexto, segundo suas preferências e valores; c) os objetivos devem ser resultado não só dos valores individuais dos gestores, mas também de como esses valores são influenciados pelo cenário em que estão inseridos; d) a construção do modelo de gestão do desempenho necessita da participação do gestor, para garantir a construção do seu conhecimento sobre o problema e ter autenticidade; e) o modelo deve, em cada uma das etapas de construção e de uso, ter o reconhecimento do gestor.

As empresas familiares, segundo Habbershon e Williams (1999), têm sido enquadradas em diversas pesquisas como extremamente complexas, dinâmicas e ricas em recursos intangíveis. Pode-se afirmar, então, que a gestão do desempenho organizacional nas empresas familiares torna-se uma ferramenta de extrema importância. 


\section{METODOLOGIA}

Neste trabalho realizou-se uma pesquisa de natureza exploratória, que de acordo com Gil (2008, p. 27) "pesquisas exploratórias são desenvolvidas com o objetivo de proporcionar visão geral, de tipo aproximativo, acerca de determinado fato".

Quanto aos procedimentos o método escolhido foi o estudo de caso, que, segundo Yin (2001, p. $32-$ 33) é "uma investigação empírica que investiga um fenômeno contemporâneo dentro de seu contexto da vida real, especialmente quando os limites entre o fenômeno e o contexto não estão claramente definidos". Dentre os tipos de estudo de caso, esta pesquisa caracteriza-se como estudo de caso múltiplo, sendo cada um objeto de estudo individual. Conforme Yin (2001), cada caso deve ser selecionado de forma a prever resultados semelhantes ou produzir resultados contrastantes apenas por razões previsíveis.

Para a seleção da população de pesquisa, as empresas foram selecionadas em uma amostra não probabilística e intencional. Assim, a população compreendeu quatro empresas com controle e gestão familiar. O Quadro 2 apresenta a caracterização da amostra.

Quadro 2 - Amostra da pesquisa

\begin{tabular}{|l|l|l|l|l|}
\hline & \multicolumn{1}{|c|}{ EMPRESA A } & EMPRESA B & \multicolumn{1}{|c|}{ EMPRESA C } & EMPRESA D \\
\hline SEGMENTO & Construção Civil & Construção Civil & Construção Civil & Construção Civil \\
\hline ESPECIALIDADE & $\begin{array}{l}\text { Fabricação de } \\
\text { equipamentos para } \\
\text { ensaios }\end{array}$ & $\begin{array}{l}\text { Fabricação de } \\
\text { máquinas } \\
\text { (laboratórios) }\end{array}$ & $\begin{array}{l}\text { Fabricação de } \\
\text { equipamentos }\end{array}$ & $\begin{array}{l}\text { Fabricação de } \\
\text { equipamentos para } \\
\text { medição }\end{array}$ \\
\hline FUNDAÇÃO & 150 & 220 & 255 & 100 \\
\hline $\begin{array}{l}\text { GERAÇÃO NO } \\
\text { COMANDO }\end{array}$ & 1953 & 1956 & 1995 & 2000 \\
\hline FATURAMENTO & $\mathrm{R} \$ 70.000 .000$ & $\mathrm{R} \$ 80.000 .000$ & $\mathrm{R} \$ 75.000 .000$ & $\mathrm{R} \$ 25.000 .000$ \\
\hline
\end{tabular}

Fonte: Dados da pesquisa

Como técnica para coleta de dados utilizou-se a entrevista semiestruturada. Foram realizadas quatro entrevistas em profundidade com o controller de cada organização, cada uma com duração aproximada de quarenta minutos, gravadas e transcritas com a permissão dos entrevistados. Com relação à identificação das empresas e dos entrevistados, Yin (2001, p. 176) aponta que em alguns casos o anonimato se faz necessário, quando o estudo de caso for sobre algum tópico polêmico ou sobre a divulgação dos resultados, para proteger os participantes. Condição esta que será respeitada nesta pesquisa, visto que se trata de 
assuntos relativos à estratégia das empresas, portanto, os nomes das empresas e dos entrevistados foram suprimidos.

As entrevistas com os controllers foram realizadas a partir de um roteiro de entrevistas, construído com base no quadro de assuntos demonstrado no Quadro 3.

\section{Quadro 3 - Quadro de assuntos}

\begin{tabular}{|c|c|c|}
\hline Assunto & Subtítulo & Autor \\
\hline \multirow{2}{*}{$\begin{array}{l}\text { Cultura organizacional e } \\
\text { Empresas familiares }\end{array}$} & Empresas Familiares & Donnelley (1964); \\
\hline & Valores do fundador & Maia (2009); Beuren e Müler (2010) \\
\hline \multirow{2}{*}{$\begin{array}{l}\text { Tomada de decisão e } \\
\text { competitividade em empresas } \\
\text { familiares }\end{array}$} & Tomada de decisão & Maia (2009); Barbosa, Costa e Souza (2013) \\
\hline & Competitividade & $\begin{array}{l}\text { Benedicto e Padoveze (2005); Chrisman, Chua e Steier } \\
\text { (2008) }\end{array}$ \\
\hline \multirow{2}{*}{$\begin{array}{l}\text { Cultura organizacional em } \\
\text { Empresas familiares }\end{array}$} & Conflitos & Bethlem (1994); Cater e Shwab (2008); Maia (2009) \\
\hline & Fraquezas & Donnelley (1964) \\
\hline \multirow{4}{*}{ Indicadores de Desempenho } & Criação de Indicadores & Almeida et al. (2012) \\
\hline & Indicadores financeiros & Beuren e Dallabona (2015) \\
\hline & Indicadores não financeiros & Almeida, Callado e Callado (2008b); \\
\hline & Indicadores e a Estratégia & Andrade, Callado e Callado (2009) \\
\hline \multirow{5}{*}{$\begin{array}{l}\text { Gestão de Desempenho } \\
\text { Organizacional }\end{array}$} & $\begin{array}{l}\text { Gestão do desempenho e o } \\
\text { reflexo financeiro }\end{array}$ & Beuren e Marcello (2016) \\
\hline & $\begin{array}{l}\text { Desempenho e } \\
\text { competitividade }\end{array}$ & Bortoluzzi, Ensslin e Ensslin (2011) \\
\hline & Crise no setor & Beuren e Marcello (2016) \\
\hline & Medição do desempenho & Benedicto e Padoveze (2005) \\
\hline & $\begin{array}{l}\text { Gestão do desempenho em } \\
\text { empresas familiares }\end{array}$ & Silva (2014); Teló (2001) \\
\hline
\end{tabular}

Fonte: Dados da pesquisa

Através das entrevistas buscou-se identificar como a cultura organizacional em empresas familiares afeta a gestão de desempenho. Após a coleta de dados, as entrevistas foram organizadas e analisadas com o objetivo de contemplar a proposta de trabalho deste artigo. Os resultados desta pesquisa são apresentados na seção seguinte. 
DISCUSSÃO DOS RESULTADOS

Apresenta-se neste capítulo, uma exposição sintética sobre as empresas estudadas. Conforme mencionado anteriormente, tratam-se de empresas familiares no ramo da construção civil, situadas no estado de São Paulo.

\section{Aspectos Sobre Cultura Organizacional}

Quando questionados sobre a existência de membros da família na gestão da empresa e quais cargos ocupam, o entrevistado $A$ afirma que há uma estrutura multi-familiar com duas famílias na gestão. $O$ entrevistado B afirma que a gestão da empresa é composta pelo patriarca e um filho, o patriarca é presidente e o filho é diretor financeiro. Na empresa $C$, são dois irmãos que gerem a empresa, um irmão é presidente e o outro diretor. Na D, o patriarca e o filho são responsáveis pela gestão, o patriarca é diretor administrativo e o filho financeiro.

As respostas dos entrevistados corroboram com o que foi afirmado por Chrisman, Chua e Sharma (2005) quando disseram que a caracterização de uma empresa familiar se dá pela influência da família na gestão.

A empresa tem uma estrutura multi-familiar (são duas famílias acionistas), com membros da primeira e segunda geração atuantes na gestão. - Entrevistado A

Ao serem questionados sobre o que consideram que é cultura para a organização, o entrevistado $\mathrm{A}$ afirmou que para a empresa é o hábito de se fazer as coisas da forma do dono. $O$ entrevistado $B$ afirmou que a cultura está ligada aos valores que a empresa possui, como o relacionamento com os clientes. Para o entrevistado $C$ a cultura na empresa é o espelho de seus gestores. Já para o entrevistado $D$ a cultura são as características que criam identidade na organização.

Já quando questionados se a cultura adotada na empresa é reflexo dos valores do fundador, o entrevistado $A$ afirmou que a cultura está relacionada aos valores do mais antigo gestor. Os entrevistados $B$, C e D acreditam que sim, é reflexo dos valores do fundador.

As respostas atestam o que Ferreira e Lourenço (2012) afirmam quando disseram que em empresas familiares, o fundador normalmente é o principal administrador, e a cultura organizacional, é um reflexo dos seus valores e crenças.

Eu diria que a cultura está relacionada ao mais antigo gestor de uma das famílias, no negócio há 50 anos. O perfil encontrado, que remete a valores ou não, é a forma simples de se fazer as coisas, sem burocracia. - Entrevistado $\mathrm{A}$ 


\section{Aspectos Sobre a Gestão da Organização}

Quando questionados se há interferência da família na tomada de decisão, todos os entrevistados afirmam que sim. Já quando questionados se existe algum membro da família que embora não participe da administração, interfira nas decisões, os entrevistados $A$ e $D$ afirmam que existe sim, a família leva as questões da empresa para casa. Os entrevistados B e $C$ afirmam há dois irmãos que não fazem parte da administração, mas sempre participam das decisões.

As respostas ratificam o que foi afirmado por Borges, Brito e Lescura (2012) quando disseram que a empresa é familiar quando há aspectos do universo familiar nos negócios, e assuntos pertinentes à empresa presentes em discussões familiares.

Existe sim, os filhos, marido, que não atuam, mas sempre são envolvidos nas discussões. Ou seja, a família leva as questões da empresa para casa e pedem por orientações, porém, por não estarem envolvidas com os negócios, nem sempre esses membros têm as informações necessárias para dar uma opinião. - Entrevistado A

Quando questionados se existe conflitos entre familiares relacionados à gestão, os entrevistados $\mathrm{Ae}$ $B$ afirmam que diariamente há conflitos, o entrevistado $C$ afirma que se há não é explícito, e na empresa $D$ não há. Já quando questionados se esses conflitos impedem o desenvolvimento da empresa, o entrevistado A afirma que na maioria das vezes sim, o lado emocional e interesses próprios são maiores que os da empresa. O entrevistado B afirma que sim, pois esses conflitos tornam a tomada de decisão tardia. Já os entrevistados $C$ e $D$ afirmam que não afetam, por não haver.

As respostas corroboram o que Maia (2009) afirma, quando diz que, a empresa e a família possuem características opostas, uma voltada para a eficiência e eficácia, e outra para aspectos afetivos, logo, essa divergência promove conflitos.

Diariamente, há desacordos entre pai e filho, e, entre as famílias entre si. Muitas vezes os funcionários ficam "no meio" desses conflitos e algumas decisões demoram tanto que quando são tomadas já é tarde demais... quase sempre está envolvido o lado emocional (traz a vida familiar para a empresa), e interesses próprios ou da família são maiores que os da empresa, não só impedindo o desenvolvimento, mas comprometendo processos já definidos. Entrevistado A

Quando questionados sobre as principais fragilidades da empresa por ser familiar, os entrevistados A e $C$ afirmam que é a falta de controles e processos. Os entrevistados $B$ e $D$ afirmam que é o fato de não ter um planejamento de longo prazo. 
As respostas confirmam o que Donnelley (1964) afirma, quando menciona as principais fraquezas da administração familiar como sendo: conflitos de interesse entre a família e a empresa, lentidão nas reações das imposições do mercado e nepotismo.

Acredito que seja a falta de processos e controles, muitas vezes os próprios gestores ignoram os processos implantados; não tem um planejamento estratégico claro, ou seja, os próprios envolvidos na gestão não sabem definir o plano; governança fraca; não há meritocracia e sim nepotismo, muitas vezes colocando familiares como diretores pelo simples fato de pertencerem a família. - Entrevistado $\mathrm{A}$

Quando questionados se a empresa se torna mais ou menos competitiva com o modelo de gestão adotado, o entrevistado $A$ afirma que se torna menos competitiva. Já os entrevistados $B, C$ e $D$ afirmam que não há interferência na competitividade.

\begin{abstract}
Menos competitiva e ineficiente. Hoje, digo que para sobrevivência e perpetuidade das empresas familiares, tem de se haver um modelo de gestão eficiente e planejamento estratégico de longo prazo, ao contrário do cenário em que estamos inseridos, onde as decisões são para atender o curto prazo, e quando se fala em plano estratégico de longo prazo, os gestores não dão importância. - Entrevistado $\mathrm{A}$
\end{abstract}

Neste quesito de competitividade, as respostam não validam o que é afirmado por Benedicto e Padoveze (2005), do qual os instrumentos de gestão baseados na cultura organizacional seriam importantes para momentos de mudança. Há indícios que a preocupação é mais imediatista do que estratégica.

\title{
Aspectos Sobre a Gestão do Desempenho Organizacional
}

Quando questionados sobre quais indicadores financeiros utilizados, o entrevistado $A$ afirma que são utilizados o índice de liquidez, fluxo de caixa, medição de custos e gastos operacionais. Já os entrevistados $B, C$ e $D$ afirmam que utilizam os índices de liquidez e fluxo de caixa.

As respostas confirmam o que Beuren e Dallabona (2015) afirmam, quando destacam que os indicadores financeiros mais utilizados são: indicadores de liquidez, indicadores de rentabilidade, indicadores de endividamento, entre outros.

Com relação aos indicadores não financeiros utilizados, o entrevistado A afirma que são utilizados indicadores de satisfação dos clientes, produtividade e qualidade dos produtos. $O$ entrevistado $B$ afirma que além dos mencionados pela empresa $A$, utilizam o indicador de compromisso de entrega. Os entrevistados $C$ e $D$ afirmam que utilizam indicadores de satisfação dos clientes, produtividade e qualidade. Todos afirmam que os indicadores são utilizados e atualizados mensalmente. O Quadro 5 apresenta os principais indicadores utilizados pelas empresas. 


\section{Quadro 5 - Indicadores de desempenho utilizados}

\begin{tabular}{|l|l|l|}
\hline \multicolumn{1}{|c|}{ Empresa } & \multicolumn{1}{|c|}{ Indicadores financeiros } & \multicolumn{1}{c|}{ Indicadores não financeiros } \\
\hline A & $\begin{array}{l}\text { Índice de liquidez, fluxo de caixa, medição } \\
\text { de custos e gastos operacionais }\end{array}$ & $\begin{array}{l}\text { Satisfação dos clientes, produtividade e qualidade dos } \\
\text { produtos }\end{array}$ \\
\hline B & Índices de liquidez e fluxo de caixa & $\begin{array}{l}\text { Satisfação dos clientes, produtividade, qualidade dos } \\
\text { produtos e compromisso de entrega }\end{array}$ \\
\hline C & Índices de liquidez e fluxo de caixa & Satisfação do cliente, produtividade e qualidade \\
\hline D & Índices de liquidez e fluxo de caixa & Satisfação do cliente, produtividade e qualidade \\
\hline
\end{tabular}

Fonte: Dados da pesquisa

Ao serem questionados sobre como surge um novo indicador, o entrevistado $A$ afirma que surge quando há necessidade de novos controles. Os entrevistados B, C e D afirmam que surgem de acordo com a necessidade de cada gestor. Com relação à avaliação da funcionalidade dos indicadores, todos os entrevistados afirmam que essa avaliação é realizada mensalmente.

As respostas ratificam o que Bititci, Carrie e Suwignjo (2000) mencionaram, quando afirmaram que a gestão do desempenho é um processo dinâmico, ou seja, ao longo do tempo as medidas a serem avaliadas vão mudar.

Nas próprias reuniões de resultado verifica-se se os indicadores estão sendo suficientes ou se há necessidade de criação de outros. - Entrevistado A

Quando questionados se acreditam que a gestão do desempenho organizacional contribui para um melhor desempenho financeiro, o entrevistado $A$ acredita que essa é a base. Os entrevistados $B, C$ e $D$ acreditam que com uma boa gestão do desempenho, os resultados são alcançados.

As respostas atestam o que foi afirmado por Ceretta e Quadros (2003) quando disseram que a gestão do desempenho se torna ferramenta gerencial, de extrema importância para que se possa atingir os objetivos propostos com sucesso.

Sim, essa é a base. Gestão, planejamento estratégico, controle, processos, meritocracia, metas, tudo remete a melhora do desempenho. - Entrevistado $A$

Para verificar se acreditam que as empresas que fazem gestão do desempenho possuem maior competitividade, os entrevistados A e B afirmam que com um bom modelo de gestão a empresa estará preparada para qualquer momento ou necessidade de mercado. Os entrevistados C e D afirmam que sim. As respostas corroboram com o estudo de Kaplan e Norton (2004), quando evidenciaram que, a pratica da gestão do desempenho cria um diferencial com relação aos concorrentes. 
A grande máxima! Você só controla aquilo que você mede. Eu diria que com um bom modelo de gestão, a empresa estará preparada para qualquer momento ou necessidade de mercado. Às vezes, se antecipada à concorrência. - Entrevistado $A$

Para a variável de demandas externas, foi questionado se acreditam que durante períodos de crise a gestão do desempenho torna-se uma importante ferramenta, o entrevistado A afirma que sim, nos três cenários, antes, durante e depois. Os entrevistados B e C afirmam que uma boa gestão através de controles, torna-se imprescindível nesses períodos. $O$ entrevistado $D$ afirma que sim, consegue controlar processos antes não vistos.

As respostas atestam o que foi afirmado por Neely (1999) quando disse que a razão pelo interesse em medição de desempenho das empresas se deu pelo aumento da concorrência e a modificação das demandas externas.

Sem dúvida! Nos três cenários. Antes, por antever os sinais da crise e estar preparado; durante, por fazer os ajustes necessários a tempo; e depois, para saber quando e o que fazer para retomada. - Entrevistado A

\section{Aspectos Sobre a Gestão do Desempenho e a Cultura Organizacional}

Em determinado momento da entrevista, foi perguntado se o fato de ser familiar afeta como a empresa lida com os indicadores, todos os entrevistados afirmam que sim, pois não se dá devida importância para o que é apontado.

As respostas atestam o que foi afirmado por Maia (2009) quando disse que, devido a essa influência da família nos aspectos administrativos, a profissionalização desse tipo de organização torna-se um desafio.

Não se dá devida importância para o que é apontado, ou não se toma providências por acharem trabalhoso. - Entrevistado A

Na realidade a família parece não dar devida importância aos indicadores, talvez pelo fato de não depender financeiramente deste negócio. - Entrevistado $C$

Quando questionados se os gestores interferem na implantação de novos indicadores, o entrevistado A afirma que sempre há interferência, pois eles acham desnecessários. Já os entrevistados $B, C$ e $D$ afirmam que não há essa interferência, geralmente quem decide é o gestor da área. Já com relação à medição de desempenho, os entrevistados A e C afirmam que os gestores não dão devida importância. Já os entrevistados $B$ e $D$ afirmam que sim, inclusive cobram resultados.

$\mathrm{Na}$ maioria das vezes os gestores não gostam de ser cobrados, por isso acham certos indicadores desnecessários. - Entrevistado A 
Em relação à preparação dos gestores, foi questionado se os gestores estão preparados para gerir o desempenho, os entrevistados A, C e D afirmam que não estão. Já o entrevistado B afirma que nem sempre estão. As respostas atestam o que foi corroboram com o que foi afirmado por Silva (2014) quando disse que, uma gestão ineficaz originada pelo despreparo dos gestores, conduz a empresa à mortalidade.

Não estão. Os filhos tiveram que assumir após a morte do pai, então ainda estão se aperfeiçoando, porém, contam com conselheiros que os ajudam na administração da empresa. As coisas vêm mudando nos últimos anos, mas ainda não tem a cara de uma empresa que busca bons resultados. - Entrevistado C

Quando questionados se os gestores da empresa estão atualizados com relação ao desempenho, o entrevistado A afirma que não completamente, apenas ao que julgam relevante. Já os entrevistados $B, C$ e D afirmam que sim.

No todo não, apenas uma visão turva. Apenas olham um ou dois fatores relevantes, o que não é suficiente. Exemplo: estão mais preocupados com a receita do que com a rentabilidade e retorno do negócio. - Empresa $A$

Quando questionados se a cultura adotada cria dificuldade na implementação de novos indicadores, o entrevistado A afirma que o que cria dificuldade é o modelo de gestão centralizador. Os entrevistados B, C e $D$ afirmam que não. Já quando questionados se os indicadores utilizados atualmente estão ligados aos valores do fundador, os entrevistados $A$ e $C$ afirmam que não. Já os entrevistados $B$ e $D$ afirmam que sim, estão ligados aos valores do fundador.

Não estão ligados pelo fato de que, o sócio de maior atuação, tem uma visão voltada somente a receita. Os indicadores implantados nasceram com base em medir a eficiência e rentabilidade do negócio. - Entrevistado A

Aos valores do fundador não, quando a empresa foi fundada os valores eram outros, outra época, outra forma de administração. Após os filhos assumirem, muitas coisas mudaram, hoje os indicadores são utilizados conforme as necessidades atuais do negócio. Entrevistado C

A personalização no processo de condução da gestão do desempenho, apesar de ser considerado por Bortoluzzi, Ensslin e Ensslin (2011) como importante; vê-se que os entrevistados não são unânimes, dos quais a personalização pode ser entendida como uma dificuldade e, em outras empresas, já estão se adaptando às necessidades do negócio.

Diante dos resultados discutidos nesta seção, foi possível constatar que, em nossa amostra, apenas dois itens não corroboram com a literatura anterior, conforme Quadro 6, que ambos estão relacionados com 
o conceito de competitividade. Observa-se que, nestas entrevistas, a competitividade não é vista como um valor claro e diferencial nestas empresas familiares.

\section{Quadro 6 - Resumo dos resultados}

\begin{tabular}{|c|c|c|c|}
\hline Assunto & Subtítulo & Autor & Resultados \\
\hline \multirow{2}{*}{$\begin{array}{l}\text { Cultura organizacional e } \\
\text { Empresas familiares }\end{array}$} & Empresas Familiares & Donnelley (1964); & Confirmado \\
\hline & Valores do fundador & $\begin{array}{l}\text { Maia (2009); Beuren e } \\
\text { Müler (2010) }\end{array}$ & Confirmado \\
\hline \multirow{2}{*}{$\begin{array}{l}\text { Tomada de decisão e } \\
\text { competitividade em empresas } \\
\text { familiares }\end{array}$} & Tomada de decisão & $\begin{array}{l}\text { Maia (2009); Barbosa, } \\
\text { Costa e Souza (2013) }\end{array}$ & Confirmado \\
\hline & Competitividade & $\begin{array}{l}\text { Benedicto e Padoveze } \\
\text { (2005); Chrisman, Chua } \\
\text { e Steier (2008) }\end{array}$ & Divergente \\
\hline \multirow[t]{2}{*}{$\begin{array}{l}\text { Cultura organizacional em } \\
\text { Empresas familiares }\end{array}$} & Conflitos & $\begin{array}{l}\text { Bethlem (1994); Cater e } \\
\text { Shwab (2008); Maia } \\
(2009)\end{array}$ & Confirmado \\
\hline & Fraquezas & Donnelley (1964) & Confirmado \\
\hline \multirow{4}{*}{ Indicadores de Desempenho } & Criação de Indicadores & Almeida et al. (2012) & Confirmado \\
\hline & Indicadores financeiros & \begin{tabular}{|lll} 
Beuren & e & Dallabona \\
$(2015)$ & & \\
\end{tabular} & Confirmado \\
\hline & Indicadores não financeiros & $\begin{array}{l}\text { Almeida, Callado e } \\
\text { Callado (2008b); }\end{array}$ & Confirmado \\
\hline & Indicadores e a Estratégia & $\begin{array}{l}\text { Andrade, Callado e } \\
\text { Callado (2009) }\end{array}$ & Confirmado \\
\hline \multirow{5}{*}{$\begin{array}{l}\text { Gestão de Desempenho } \\
\text { Organizacional }\end{array}$} & $\begin{array}{l}\text { Gestão do desempenho e o } \\
\text { reflexo financeiro }\end{array}$ & $\begin{array}{lll}\text { Beuren e } & \text { Marcello } \\
(2016) & & \\
\end{array}$ & Confirmado \\
\hline & Desempenho e competitividade & $\begin{array}{l}\text { Bortoluzzi, Ensslin e } \\
\text { Ensslin (2011) }\end{array}$ & Divergente \\
\hline & Crise no setor & $\begin{array}{|lll|}\text { Beuren e } & \text { Marcello } \\
(2016) & & \\
\end{array}$ & Confirmado \\
\hline & Medição do desempenho & $\begin{array}{l}\text { Benedicto e Padoveze } \\
(2005)\end{array}$ & Confirmado \\
\hline & $\begin{array}{l}\text { Gestão do desempenho em } \\
\text { empresas familiares }\end{array}$ & Silva (2014); Teló (2001) & Confirmado \\
\hline
\end{tabular}

Fonte: Dados da pesquisa 


\section{CONCLUSÃO}

As empresas familiares ocupam posição significativa na economia brasileira e mundial, estando presentes em diferentes setores, desde pequenas empresas até grandes multinacionais (BEUREN, HEIN e ORO, 2009; BEUREN e GRANDE, 2011). Entretanto, os aspectos culturais nesse tipo de organização possuem características específicas, pois envolvem a família nas decisões administrativas (MAIA, 2009; BEUREN e MÜLER, 2010). Devido a essa influência, a profissionalização desse tipo de organização torna-se um desafio (MAIA, 2009; BARBOSA, COSTA e SOUZA, 2013). Deste modo, as empresas familiares que fazem gestão do desempenho enquadram-se nesse perfil.

O objetivo desta pesquisa foi avaliar os principais aspectos culturais em empresas familiares e como eles podem afetar a gestão do desempenho organizacional. Para tal, pretendeu-se responder ao seguinte questionamento: Como a cultura organizacional afeta a "gestão de desempenho" de uma empresa familiar?

Foram encontradas diversas características familiares nas empresas estudadas, conforme preconizado na literatura. Observou-se que em todas as empresas estudadas há presença da família na gestão, e todos os entrevistados acreditam que a cultura adotada na empresa é o reflexo dos valores do fundador.

Com relação aos aspectos da gestão, em todas as empresas a tomada de decisão, mesmo que parcialmente, é centralizada nos fundadores, além de haver uma presença forte nas decisões por integrantes da família que não participam da administração. Ficou claro que os entrevistados acreditam que a principal fragilidade das empresas é a falta de planejamento estratégico e controles.

Quanto à existência de indicadores, as empresas estudadas utilizam como ferramenta de gestão do desempenho, indicadores financeiros e não financeiros. Entretanto ambos concordam que o fato de ser familiar afeta como a empresa lida com esses indicadores, pois, de certa forma os administradores não dão devida importância ao que é apontado, além de acreditarem que, embora atualizados com relação ao desempenho, os gestores nem sempre estão preparados para geri-lo. Contudo, os entrevistados acreditam que as empresas que fazem gestão do desempenho possuem maior competitividade e reflexo no desempenho financeiro.

Conclui-se que as práticas de gerir o desempenho organizacional nas empresas familiares investigadas sofrem grande influência da cultura organizacional, consequentemente dos valores do fundador.

Esta pesquisa contribuiu para relacionar os aspectos culturais e como as empresas familiares fazem gestão do desempenho, que poderão servir de referência para pesquisadores que venham interessar-se pela temática discutida, visto que muitos dos estudos realizados até o momento não investigaram os dois aspectos de forma conjunta. Há fortes evidencias de que a forma como os gestores familiares lidam com os indicadores de desempenho possam influenciar os resultados da empresa familiar.

Esta pesquisa oferece também contribuições gerenciais para o campo empresarial, oferecendo informações aos administradores de empresas familiares e a outros interessados, possibilitando a reflexão e avaliação do comportamento gerencial adotado, considerando que estes buscam a permanência de sua empresa no mercado. 
Entende-se como a principal limitação, o número reduzido de empresas estudadas, uma vez que o estudo compreendia assuntos relativos à estratégia, logo, muitas empresas não aceitaram participar da pesquisa.

Por fim, para futuras pesquisas, recomenda-se a realização desse tipo de análise em segmentos variados; com uma amostra maior de empresas do mesmo segmento; em empresas familiares de grande porte; e, estudos que abordem fatores não considerados por esse trabalho.

\section{REFERÊNCIAS}

ABREU, L. F. et al. Modelo de avaliação de desempenho logístico com base no balanced scorecard: proposta para uma pequena empresa. Revista da Micro e Pequena Empresa, v.2, n.1, pp. 19-37, 2008.

ALBUQUERQUE, A. L.; OLIVEIRA, J. L.; PEREIRA, R. D. Governança, sucessão e profissionalização em uma empresa familiar: (re)arranjando o lugar da família multigeracional. Revista Brasileira de Gestão de Negócios, v.14, n.43, pp. 176192, abr./jun., 2012.

ALMEIDA, M. A. et al. Relacionando fatores contingenciais com o uso de indicadores de desempenho em empresas do Porto Digital. Revista de Negócios, v.17, n.3, pp.20-35, jul./set., 2012.

ALMEIDA, M. A.; CALLADO, A. A. C.; CALLADO, A. L. C. Determinando padrões de utilização de indicadores de desempenho: um estudo em micro e pequenas empresas da cidade de João Pessoa. Revista UnB Contábil, v.11, n. 1-2, pp. 18-29, jan./dez., 2008a.

ALMEIDA, M. A.; CALLADO, A. A. C.; CALLADO, A. L. C. A utilização de indicadores de desempenho não-financeiros em organizações agroindustriais: um estudo exploratório. Revista Organizações Rurais \& Agroindustriais, v.10, n.1, pp. 3548, 2008b.

ALTAF, J.G.; TROCCOLI, I. R. A importância da gestão profissional em uma empresa familiar - Joalheria Meridiano Ltda. Revista Economia e Gestão, v.10, n. 23, pp. 40-59, mai./ago., 2010.

ANDRADE, L. P.; CALLADO, A. A. C.; CALLADO, A. L. C. Relação entre indicadores de desempenho: um estudo exploratório em empresas localizadas em Serra Talhada/PE. Revista de Negócios, v.14, n.1, pp. 100-114, jan./mar., 2009.

BARBOSA, F. V.; COSTA, D. M.; SOUZA, P. C. M. Fatores que dificultam a gestão em empresas familiares: um estudo em uma prestadora de serviços de RH. Revista Ciências Sociais em Perspectiva, v.12, n.22, 2013.

BEGEMANN, C.; BITITCI, U. S.; TURNER, T. Dynamics of performance measurement systems. International Journal of Operations and Production Management, v.20, n.6, pp. 692-704, 2000.

BENEDICTO, G. C.; PADOVEZE, C. L. Cultura organizacional: análise e impactos dos instrumentos no processo de gestão. Read, v.11, n.2, mar./abr., 2005.

BERNHOEFT, R. Empresa familiar: sucessão profissionalizada ou sobrevivência comprometida. São Paulo: Ibecon, 1987.

BETHLEM, A. S. A empresa familiar: oportunidades para pesquisa. Revista de Administração, v.29, n.4, pp. 88-97, out./dez., 1994.

BEUREN, I. M.; DALLABONA, L. F. Relação da folga organizacional com medidas de desempenho de empresas brasileiras. Revista Pretexto, v.16, n.2, pp. 31-49, abr./jun., 2015.

BEUREN, I. M.; GRANDE, J. F. Mudanças de práticas de contabilidade gerencial identificadas nos relatórios da administração de empresas familiares. Revista Contabilidade, Gestão e Governança, v.14, n.3, pp. 18-33, set./dez., 2011.

BEUREN, I. M.; MARCELLO, I. E. Relação da importância dos recursos estratégicos com as medidas de desempenho em empresas brasileiras. Revista Ibero-Americana de Estratégica, v.15, n.1, jan./mar., 2016.

BEUREN, I. M.; MÜLER, E. T. C. Estrutura formal e práticas da controladoria em empresas familiares brasileiras. Revista Gestão \& Regionalidade, v.26, n.76, jam./abr., 2010.

BEUREN, I. M.; HEIN, N.; ORO, I. M. Análise da eficiência de empresas familiares brasileiras. FGV-EAESP/ERAeletrônica, v.8, n.2, jul./dez., 2009.

BITITCI, U. S.; CARRIE, A.S.; SUWIGNJO, P. Quantative models for performance measurement system. Elsevier Science, v.64, pp. 231-241, 2000.

BORGES, A. F.; BRITO, M. J.; LESCURA, C. Relações de parentesco em empresas familiares: uma abordagem sócio antropológica. Gestão Org, v.10, n.3, pp. 595-622, set./dez., 2012.

BORGES, J. G.; CARVALHO, M. M. Sistema de indicadores de desempenho em projetos. Revista de Gestão e Projetos - GeP, v.2, n.1, pp. 174-207, jan./jun., 2011. 
BORTOLUZZI, S. C.; ENSSLIN, L.; ENSSLIN, S. R. Metodologia multicritério para avaliação de desempenho da gestão em uma empresa familiar. Gestão da Produção, Operações e Sistemas, ano 6, n.3, pp. 109-127, jul./set., 2011.

CARIO, S. F.; LISONI, J.; PEREIRA, M. F.; RIBEIRO, M. L. G. Processo de mudança e adaptação estratégica em uma empresa familiar brasileira: o caso da Reunidas S/A. Organização em contexto, v.6, n.11, pp. 86-124, jan./jun., 2010.

CATER, J.; SCHWAB, A. Turnaround strategies in established small Family firms. Family business review, v.21, n.1, pp. 31-50, mar.,2008.

CELESTINO, M. S.; SILVA, J. D. G. O balanced scorecard como framework para a ação estratégica. Revista IberoAmericana de Estratégica, v.10, n.3, pp. 147-172, set./dez., 2011.

CERETTA, P. S.; QUADROS, C. J. Implantação do balanced scorecard: um caso prático. Read, v.9, n.4, pp. 1-18, jul./ago., 2003.

CHRISMAN, J. J.; CHUA, J. H.; SHARMA, P. Trends and directions in the development of a strategic management theory of the family firm. Entrepreneurship theory and practice, pp. 555-575, set., 2005.

CHRISMAN, J. J.; CHUA, J. H.; STEIER, L. Toward a theoretical basis of understanding the dynamics of strategic performance in family firms. Entrepreneurship theory and practice, pp. 935-947, nov., 2008.

CORSO, J. M.; CRUZ, J. A. W.; MARTINS, T. S. O impacto da implementação do balanced scorecard no desempenho financeiro. Revista Gestão e Planejamento, v.12, n.1, pp. 61-73, jan./jun., 2011.

CRUZ, S. F.; FERREIRA, M. M. F. Percepção de cultura organizacional e de gestão do conhecimento em hospitais com diferentes modelos de gestão. Revista de Enfermagem Referência, v.4, n.5, pp. 75-83, abr./mai./jun., 2015.

DIENG, M.; MORAES JÚNIOR, V. F.; REZENDE, I. C. C. Análise comparativa da utilização de indicadores financeiros e não financeiros em hotéis da cidade de João Pessoa - PB: um estudo com enfoque na gestão estratégica. Revista Interface. v.8, n.1, pp. 111-127, jan./jun., 2011.

DONNELLEY, R. G. La empresa familiar. Revista de Administração de Empresas, v.42, n.4, pp. 161-198, 1964.

DUTRA, A. Metodologias para avaliar o desempenho organizacional: revisão e proposta de uma abordagem multicritério. Revista Contemporânea em Contabilidade, n.3, pp. 25-56, jan./jun., 2005.

FERREIRA, P. A.; LOURENÇO, C. D. S. Cultura organizacional e mito fundador: um estudo de caso em uma empresa familiar. Gestão \& Regionalidade, v.28, n.84, set./dez., 2012.

FIESP. PIB do setor de Construção Civil caiu $2,7 \%$ no $1^{\circ}$ Trimestre do Ano, mostra estudo da FIESP. Disponível em: <http://www.fiesp.com.br/noticias/pib-do-setor-de-construcao-civil-caiu-27-no-1o-trimestre-do-ano-mostra-estudo-dafiesp/>. Acesso em 07/09/2016.

GASPARETTO, V.; LUNKES, R. J.; SCHNORRENBERGER, D. Alinhamento estratégico com o uso de uma metodologia multicritério em apoio a decisão-MCDA. Revista Gestão \& Planejamento, v.15, n.3, pp. 430-450, jul./dez., 2014.

GIL, A. C. Métodos e técnicas de pesquisa social. 6 ed. São Paulo: Atlas, 2008.

HABBERSHON, T. G.; WILLIAMS, M. L. A resource-based framework for assessing the strategic advantages of family firms. Family Business Review, v.1, pp. 122-138, 1999.

JIMÉNEZ, S. O.; MEDINA, I. L.; SILVA, B. O. Cultura organizacional y evaluación del desempeño del personal académico. Revista Electrónica Nova Scientia, v.6, n.11, pp.324-345, 2013.

KAPLAN, R. S.; NORTON, D. P. Medindo a prontidão estratégica de ativos intangíveis. Harvard Business Review, pp. 114, 2004.

$\mathrm{KICH}$, J. I. D. F.; PEREIRA, M. F. A relação entre a cultura organizacional e o processo de planejamento estratégico: um estudo de caso em uma empresa norte-americana. Revista Ibero-Americana de Estratégica, v.8, n.2, pp. 58-79, jul./dez., 2009.

LIMA, J. B.; OLIVEIRA, R. R.; OLIVEIRA, R. R. Reflexão sobre a relação entre a mudança de cultura organizacional e a gestão do conhecimento. Perspectiva em Gestão \& Conhecimento, v.6, n.1, pp. 19-35, jan./jun., 2016.

MACEDO, M. A. S.; MARQUES, J. A. V. C.; RIBEIRO, M. G. C. Análise da relevância de indicadores financeiros e não financeiros na avaliação de desempenho organizacional: um estudo exploratório no setor brasileiro de distribuição de energia elétrica. Revista de Contabilidade e Organizações, v.6, n.15, pp. 60-79, 2012.

MACEDO, M. A. S.; SILVA, F. F. Análise de desempenho organizacional: propondo uma modelagem utilizando indicadores financeiros e não financeiros na avaliação de performance empresarial. Revista Alcance, v.12, n.2, pp. 211231, mai./ago., 2005.

MAIA, T. S. T. Gestão de pessoas: particularidades de empresas familiares. Revista Pensamento Contemporâneo em Administração, v.3, n.2, mai./ago., 2009.

NEELY, A. Business performance measurement. 2 ed. Cambridge: Cambridge, 2007. 
NEELY, A. The performance measurement revolution: why now and what next? International Journal of Operations \& Production Management, v.19, n.2, pp. 205-228, 1999.

OLIVEIRA, A. P.; PAPA, A. C. A influência da cultura organizacional no processo de profissionalização da gestão em uma empresa familiar. Revista Adm. UFSM, v.2, n.3, pp. 385-398, set./dez., 2009.

RAMOS, F.; SOUZA, S. O.; WEHRLE, A. F. Cultura organizacional: um estudo de caso a partir da perspectiva dos gestores da empresa EQS Engenharia. Revista Administração em Diálogo, v.18, n.2, pp. 92-123, mai./jun./jul./ago., 2016.

RODRIGUES, A. M. Padrões efetivos na família e empresa familiar. Revista de Administração de Empresas, v.31, n.4, pp. 35-48, out./dez., 1991.

SILVA, W. R. Empresa familiar - a importância da gestão interna e externa: as vantagens e desvantagens de cada uma no processo de sucessão. Revista Especialize On-line IPOG, v.01, n.9, dez., 2014.

SOMENSI, U. F.; TONTINI, G. O balanced scorecard e seu inter-relacionamento com outros métodos de gestão. Revista de Negócios, v.6, n.1, pp. 23-31, jan./mar., 2001.

TELÓ, A. R. Desempenho organizacional: planejamento financeiro em empresas familiares. Revista FAE, v.4, n.1, pp. 1726, jan./abr., 2001.

YIN, R. K. Estudo de caso: planejamento e métodos. 2 ed. Porto Alegre: Bookman, 2001. 